\title{
The curriculum arguments of Michael Young and John White
}

\author{
Michael J Reiss
}

\begin{abstract}
Michael Young's ideas about the school curriculum have proved to be enormously fertile, in particular his thinking about 'powerful knowledge' and his argument that the main function of schools is to enable all students to acquire knowledge that takes them beyond their experience. Young's ideas are examined in this chapter, particularly in the light of John White's long-standing views about the curriculum and his argument that the main aim of schools should be to promote human flourishing. I conclude that if applied inflexibly or naively Young's ideas could result in some students receiving an inappropriate education. Applied sensitively they have the potential to complement the work of other educationalists, including John White, and enrichen the education that schools provide. A start is being made on such fine-grained work - notably in respect of geography. It would be good to see such work extended to other subjects.
\end{abstract}




\title{
The curriculum arguments of Michael Young and John White
}

\author{
Michael J Reiss
}

I work at ULC Institute of Education, having moved to the Institute of Education in 2001. This chapter, of course, is a contribution to a Festschrift for Michael Young, on the occasion of the $50^{\text {th }}$ anniversary of his arrival at the Institute of Education. By co-incidence, a couple of years back I contributed a chapter (Reiss, 2015) to a Festschrift for John White, on the occasion of the $50^{\text {th }}$ anniversary of his arrival at the Institute of Education. While the Institute of Education has had, and still does have, a number of other notable experts in curriculum matters (e.g., Denis Lawton, David Scott, Geoff Whitty), Michael Young and John White are especially well known for their writings about the curriculum. Despite this, there seems to be remarkably little written that compares their arguments. In this chapter, I start by attempting this, concentrating on the positions they have each articulated about the school curriculum in recent years rather than attempting any sort of genealogical analysis, and then use their arguments as an opportunity to reflect on issues to do with the school curriculum.

\section{Michael Young's core arguments about the school curriculum}

Michael Young's more recent arguments about the school curriculum have been coherently and powerfully expressed in a number of publications, of which perhaps the core text is his sole-authored Bringing knowledge back in (Young, 2008). In this book, as is well known, Young argues for a social realist approach to knowledge. Such an approach advances on two fronts: first, it is 'social' in that it takes seriously the fact that human knowledge is produced by groups of individuals; secondly, it is 'realist' in that "A social theory must recognize that some knowledge is objective in ways that transcend the historical conditions of its production (e.g., Euclid's geometry and Newton's physics" (Young, 2008, p.28). This social realist approach allows Young to reject both relativism and postmodernism, and also to avoid a naïve version of positivism.

As a sociologist it is unsurprising that Young makes use of Durkheim's sociology of knowledge, both in itself and through its impact on Bernstein, but perhaps more interesting is the use he makes in Bringing knowledge back in of Vygotsky, to whose work he wrote, in his typically open and refreshing way, he had recently come "for the first time" (Young, 2008, p.45). Somewhat paralleling Durkheim's famous contrast of the sacred and the profane, Vygotsky contrasted scientific and everyday concepts. In Young's words:

The main difference between the two types of concept for Vygotsky were:

1. They involve different relationships to objects. For Vygotsky, whereas a child's relationship to the world through his/her everyday concepts is through what he/she sees or experiences directly, with scientific concepts, the relationship is mediated by these concepts, and is not dependent on direct experience. 
2. The absence of a system (of relationships between concepts) was, for Vygotsky, the cardinal psychological difference distinguishing everyday from scientific concepts.

(Young, 2008, p.51)

A key conclusion that Young then reaches is that "The curriculum cannot be based on everyday practical experience. Such a curriculum would only recycle that experience" (Young, 2008. p.89). He also concludes that "It is important to be cautious about replacing a curriculum based on specialist research and pedagogic communities with one based on the immediate practical concerns of employers or general criteria for employability such as key skills" (Young, 2008, p.89).

Michael Young's ideas about the school curriculum have proved to be enormously fertile, leading him to develop and defend his views in numerous keynotes and debates and a range of publications. A convenient presentation of his recent thinking is provided by his Knowledge and the future school co-authored with David Lambert and with inputs from Carolyn Roberts and Martin Richards (Young et al., 2014). In that book, Young is explicit that "the main function of school ... is to enable all students to acquire knowledge that takes them beyond their experience (Young, 2014a, p.10). There is much in this short quotation that is notable; here let me allow Young to elaborate on his use of 'all':

The school, for all its tendencies to reproduce the inequalities of an unequal society, is the only institution we have that can, at least in principle, provide every student with access to knowledge. The only alternative to schools for all is to accept that the majority will never have the educational opportunities that the minority has always treated as their right. We must respect and value the experience of pupils, but we can never allow them to depend on their experience alone. To do so would leave them (and us) in the position of out Stone Age ancestors, or worse; we would be no different from animals, who have only their experience.

(Young, 2014a, p.13)

\section{John White's core arguments about the school curriculum}

While John White's views on the curriculum have developed over the years, they have perhaps changed less than Michael Young's have. His first book, Towards a compulsory curriculum, was published in 1973 (White, 1973). In it White advanced a number of arguments that he has then developed over many years. There is a central presumption that education must be for the benefit of individual learners and take them as its starting point:

It is at this point that notions of a 'child-centred' education and an 'integrated' education meet: the child must be at the centre of all he learns; education cannot be 'subject-centred' in this sense.

(White, 1973, p.51)

White holds that education is about far more than the acquisition of knowledge about particular subjects. One point stressed in Towards a compulsory curriculum is that pupils 
"should finish their education with an understanding of the many different ways of life which they and others may pursue" (White, 1973, pp.43-4). A further argument advanced in Towards a compulsory curriculum, in a way that goes beyond the 'forms of knowledge' of Hirst (1965), and others, is that not all school subjects are of equal worth. This argument connects with the issue of whether all ways of life are of equal worth. In contradistinction to the assumptions of recent UK governments - motivated primarily by a naive set of beliefs about the importance of home-grown science, technology, engineering and mathematics talent for economic growth - White argues that "The humanities have a more central role in the curriculum than the natural sciences ... because they alone enable one to weave together a human life" (White, 1973, p.63). Fuller treatments as to the aims of education followed, including a 1996 booklet titled The aims of school education, published by the Institute for Public Policy Research (White, 1996). In its 14 pages, possible national aims for the school curriculum are advanced and suggestions are made as to how the journey from aims to curriculum might be traversed.

A further development of what a school curriculum might look like if one were to begin with aims rather than subjects is presented in some of White's most recent writing, notably An aims-based curriculum (Reiss \& White, 2013). The intention behind this publication is to provide a framework for the development of a coherent set of aims for the curriculum, some for implementation at national level, others at the level of each school. The argument begins with the premise that the aim of the school curriculum is two-fold: to lead each learner to lead a life that is personally flourishing; and to help others to do so, too. It is then argued that a central aim of a school should therefore be to prepare students for a life of autonomous, whole-hearted and successful engagement in worthwhile relationships, activities and experiences. This aim involves acquainting students with a wide range of possible options from which to choose, though we need to recognise that students vary in the extent to which they truly are able to make such 'choices'. With their development towards autonomous adulthood in mind, schools should provide students with increasing opportunities to decide between the pursuits that best suit them. Young children are likely to need greater guidance from their teachers, just as they do from their parents. Part of the function of schooling, and indeed parenting, is to prepare children for the time when they will need to, and be able to, make decisions more independently.

John White and I went on to argue that we want children to want other people, as well as themselves, to lead fulfilling lives. This means not hurting them, not lying to them, not breaking one's word or in other ways impeding them in this. It also means helping others to reach their goals, respecting their autonomy and being fair, friendly and cooperative in one's dealings with them. Schools can reinforce and extend what parents and others in families do in developing morality in children. Schools can widen students' moral sensitivity beyond the domestic circle to those in other communities, locally, nationally and globally. They can encourage students to reflect on the basis of morality, including whether this is religious or non-religious.

As part of their moral education, schools should help students to become informed and active citizens of a liberal democratic society. This means encouraging them to take an interest in political affairs at local, national and global levels from the standpoint of a concern for the general good, and to do this with due regard to values such as freedom, 
individual autonomy, equal consideration and cooperation. Young people also need to possess whatever sorts of understanding these dispositions entail, for example an understanding of the nature of democracy, of divergences of opinion about it, and of its application to the circumstances of their own society.

As future citizens, the great majority of students will contribute to the general well-being, as well as to their own, through work. This will often be remunerated, though much of it, e.g., caring for children or elderly relatives, may not be. As autonomous beings, students will eventually have to make choices about what kind of work to engage in. Schools should be helping them in this by making them aware of a wide range of vocational possibilities and routes into them, as well as their advantages and disadvantages. This is a particularly important function of schools as this is something that few parents can provide for their children.

\section{Comparing Young and White}

There are a number of similarities in the positions of Young and White in relation to the school curriculum. In particular, both are deeply concerned with what the curriculum should be. Indeed, Young goes so far as to write: "In this chapter, we use the term 'curriculum' as a kind of shorthand for defining the purpose of a school (or, in relation to the National Curriculum, the aims of the school system of a country), whether from the perspective of a head, a subject leader, a teacher, a parent or pupil, or a minister" (Young, 2014a, p.9). Furthermore, both Young and White are concerned with issues to do with social justice. Although neither focuses on issues to do with a shortage or unequal distribution of resources (such as the distribution of teacher excellence or finance among different schools), both are very concerned with the extent to which different students should all receive the same curriculum.

Given these shared foci on curriculum aims and social justice, I want now to ask two questions raised by both Young's and White's writings: 'What place does the everyday have in powerful knowledge?' and 'Is the same knowledge powerful for all students?'.

\section{What place does the everyday have in powerful knowledge?}

Everyone, including Michael Young and John White, would surely agree that schools need to complement and build up what their students learn from their families and other extraschool sources. When I was about seven years old I got some childhood infection - measles, chickenpox or something - and missed a couple of weeks of school. On the day I returned, I can remember my teacher, with genuine concern in her voice, saying to me "We've started multiplication". "That's all right", I replied; "My mother has taught me that". And so she had. Many parents teach their children to read and start writing (and virtually all teach them to speak) but my mother had taught me at least the rudiments of my times tables.

The point is that it is precisely when some students have been taught something by their parents (or other extra-school sources) and other students have not that schools need, for 
both pedagogical and social justice reasons, to be quite skillful. If all students know $X$, then this provides a baseline from which schools can move forward. (Examples of baseline nonacademic knowledge that used to be assumed by many primary schools in England for children arriving at school for the first time included being able to go to the toilet by oneself, using a knife and fork and knowing one's name. However, I do know one woman whose primary school initially assumed she was deaf because she did not respond to her name; it turned out that neither of her parents ever used her name at home, simply calling her 'you'.) Equally, if none of the students know almost anything about $Y$ (e.g., the reason why the Periodic Table looks as it does, the past historic in French or the principle of commutativity in mathematics) a teacher can assume a level playing field. The more difficult cases for a teacher to handle are when some students - such as my younger self - do know quite a bit about a topic before it is taught in school.

This of course, raises the issue of what we mean by 'everyday'. To continue on an autobiographical theme, although my parents provided my sister and me with an intellectually rich home life, so that from a young age it was assumed that we would take place in family discussions on issues to do with politics, current affairs, literature, the arts and general ethical matters, and although we read widely and were taken on visits to museums and art galleries, our home was almost entirely empty of music. I cannot remember either of my parents ever singing and although my parents had a small number of gramophone records, beyond one playing of Prokofiev's Peter and the Wolf, I cannot recall listening to any music at home, beyond that which one would hear on Radio 4 - to which my mother listened a great deal. Unsurprisingly, both my sister and I were considered to be tone deaf when we arrived at our schools and, on seeing the looks I got from others when I tried to sing, I very rapidly learnt that the wisest course of action was to pretend to sing but to keep quiet.

The point of this touching story is that what is everyday to one student may be exotic to another. This issue is compounded by the fact that today's school students have far more avenues for extra-school learning that was once the case. When once the only way a child obsessed with the Russian Revolution was to get down to a good local library or study Jackdaw No. 42 (let the reader understand), nowadays a single internet search leads to a huge number of images, texts and video clips of both primary and secondary data. All this makes a teacher's job more challenging but also potentially more fruitful.

Neither Michael Young or John White seems particularly interested in the affordances of new technologies for learning, which is fair enough - none of us is or can be interested in everything and the educational potential of these new technologies, which were mostly hardly in existence when Michael Young and John White reached the age at which many retire, have been slower in realisation than many expected. Nevertheless, at the very least, as I have indicated, new modes of communication trouble a straightforward notion of 'the everyday'. Furthermore, what counts as 'everyday' depends not only whether or not a parent does or does not have a liking for mathematics or music but on a whole range of structural considerations so that, for instance, girls and boys often differ in the knowledge they bring to school about such topics as cookery, carpentry, technology (if anyone does carpentry anymore) and dance. 
In addition to these issues, though, there are more fundamental reasons to question Michael Young's argument, cited above, that "The curriculum cannot be based on everyday practical experience. Such a curriculum would only recycle that experience" (Young, 2008. p.89). Perhaps it depends what one means by 'base'. If one means that a curriculum should be restricted to students' everyday practical experience, then I would agree that that would seem too limiting a vision of school education. Indeed, such an education would be close to pointless - why go to school (other than for reasons of socialisation or child minding) if one is exposed to nothing more than what one already knows or is bound to acquire outside of school?

But 'base' is normally used as the starting point - not the end point (cf. the two Everest Base Camps). And here (shades of Ausubel's famous dictum) there are two main reasons for basing school teaching on everyday practical experience: one to do with motivation, the other to do with epistemology.

The motivational argument for starting from or including the everyday is obvious. For many students, certainly at secondary level, a persistent criticism they voice of much of their schooling is that it's 'not relevant'. By connecting, as a teacher, what one wants one's students to learn with the everyday, one increases the likelihood that they will find it engaging. Of course, the unfamiliar can engage too - the skill of the teacher in no small measure consists of shifting between the everyday and the exotic, the familiar and the unfamiliar, all the time trying to lead students towards a goal that quite a number of them may not initially appreciate.

To be more concrete, if in history one is trying to get students to appreciate the importance of nationalism as one of the causes of the First World War, one might choose (at the time of my writing this in 2016) to start with a class discussion about the importance of contemporary nationalism for understanding Russia's actions in Ukraine and the Crimea. The point of such teaching would not be to get one's students to become experts on the issue of Russia's contemporary military actions but to start from an issue that at least some of them will have heard of that connects with what one really wants them to learn about (the causes of the First World War). As a teacher one would also hope that students could be encouraged to come up with other explanations - e.g., the benefits to President Putin of boosting his electoral popularity, Russian fears about an expansionist NATO, etc.. Such an approach might then make it easier for students to appreciate that historians do not agree on a 'single cause' of the First World War. Depending on the age of the students, their abilities, the teacher's abilities and the demands of the curriculum a teacher might or might not want to go on to get students to appreciate the methods that historians use when trying to determine the causes of events.

In case it is objected that for most students Russia's actions in the Ukraine and the Crimea can hardly be considered as an example of the everyday, we can imagine how a teacher might use everyday understandings of the properties of ropes when teaching about current in an electric circuit. Here the point is that the everyday (an inelastic rope) serves as an analogy (or model) of electric current (the flow of charge due to the movement of electrons). A standard exercise in many schools is to get a group of, say, a dozen students to 
pass a loop of rope through their hands ${ }^{1}$. Most students are asked, passively, to let the rope pass through their slightly closed hands (analogous to being part of the conductor in the circuit, e.g., copper wire) but one student has the job of passing the rope along (analogous to being a battery) and another student is asked (health and safety alert) cautiously to tighten their hands so as to impede the passage of the rope (analogous to being a resistor, such as a bulb). Part of the skill of the teacher is subsequently to get students to think both about ways in which the rope differs from as well as is similar to electric current. In such an exercise, knowledge of the everyday is a powerful basis for the knowledge that the teacher wishes the students to acquire.

The consistent use of the everyday in school science has led to a number of innovative courses that are generally included under the heading of 'context-based curricula'. SaltersNuffield Advanced Biology (SNAB) is an example of such a course for ' $A$ ' level biology students (typically 16-18 year-olds). It is taught through real-life biological contexts. For example, most advanced level biology courses start with cell biology or biochemistry. SNAB don't. It starts with an account of Mark, a 15 year-old who had a stroke, and Peter, an adult who had a heart attack. It then goes on from the details of their cases to look at why some people suffer from cardiovascular disease. This allows the course to introduce the biochemistry of fats and carbohydrates bit by bit, as students need to know them to understand about strokes and heart diseases, rather than all at once. Similarly, transport across membranes - a most important part of any advanced level biology course - is dealt with in the context of cystic fibrosis. Cystic fibrosis is quite a common disease and looking at it also allows SNAB to introduce other aspects of biology such as some genetics, since cystic fibrosis is an inherited condition (Reiss, 2005).

The epistemological argument for starting from or including the everyday is perhaps less obvious than the motivational one. We can illustrate it by referring back to the example of the causes of the First World War. As any historian knows, wars have a number of causes. Knowing about the causes of the First World War will help one more rapidly to understand about the causes of the Hundred Years' War, the American Civil War and the Second World War but not through a trite transfer of knowledge about the causes of the First World War to these other three examples. Each requires study in its own right. David Lambert makes the same point in more detail in his chapter in this volume with regards to geographical knowledge: though cities have certain commonalities (as do wars) each is distinct and requires study in its own right. Quotidian occurrences are specific in time and in place.

Of course, it might be objected that what I have said about geography and history doesn't hold about the natural sciences or mathematics. Broadly speaking I accept this to a certain extent - though Michael Young himself, somewhat in contradistinction to his 2008 quotation above about Euclid's geometry "transcend[ing] the historical conditions of its production", has pointed out how for 2000 years mathematicians presumed that Euclid's axiom that 'parallel lines never meet' was true, before work by Lobachevsky and others gave rise to non-Euclidian geometry (Young 2014a). (For non-mathematicians, the easiest way to think about non-Euclidian geometry is to imagine parallel lines not on a flat plane but on a curved surface - such as a sphere. Depending on the shape of the curved surface,

\footnotetext{
${ }^{1}$ For example, see https://www.youtube.com/watch?v=uyikV sV7ZQ from $5 \min 30 \mathrm{~s}$ to $8 \min 40 \mathrm{~s}$
} 
parallel lines may diverge or meet, as they do in lines on longitude on a globe.) How significant it is for Michael Young that the natural sciences and mathematics produce knowledge that is less tied to time and place than is knowledge produced in other subjects may be connected to the fact that he is a chemist by background (whereas John White was a historian). There's a story (? exaggerated) related by Paul Ehrlich of how, at a meeting in Stockholm to do with human population size, economists kept proposing solutions to the problems of increasing population size that, on examination, proved to entail a violation of the Second Law of Thermodynamics. The physicists and biologists kept pointing this out. "Finally, in frustration, one of the economists blurted out, 'Who knows what the second law of thermodynamics will be like in a hundred years?'” (Ehrlich, 1981, p.28). Yes, the Second Law of Thermodynamics is not likely to change but in my own science discipline (biology) there is a wonderful interplay between the local and transient (think of the specificity of species distributions over time and space) and the longer-lasting and more widely distributed (think of the near-universality of the genetic code).

\section{Is the same knowledge powerful for all students?}

Finally, I want to look at a key issue: Is the same knowledge powerful for all students? At the risk of simplifying the arguments of both Michael Young and John White, while both are committed, as I have pointed out, to social justice, their positions differ with respect to the extent to which the same knowledge is powerful for all students. Of the two, John White is more explicit about the issue. While he does not use the word 'powerful' - except sometimes to criticise Michael Young - his emphasis is on human wellbeing, understood as human fulfillment (White, 2011) or flourishing. White's position is one that gives considerable weight to school students being provided, as they age, with increasing opportunities to choose what they study.

While neither John White nor Michael Young buys in fully to the arguments of E D Hirsch that there is a large core of knowledge that should be taught to all students (e.g, Hirsch, 1996), Michael Young is the more sympathetic of the two to Hirsch's position (cf. White, 2014b). As he puts it:

Newton and Shakespeare are historical figures who made discoveries and wrote plays in their contexts which were very different from ours. But we still go to Shakespeare's plays, and recognize that although they are about a society that we only dimply know about through history books, their characters and relationships articulate for us almost universal truths. Likewise, we find that for human beings living on this planet, Newton's laws of motion and light are as near the truth as we can get - today as they were in the 1970s, and before he discovered them in the late 1600s.

(White, 2014c, pp.65-66)

While I too still go to Shakespeare's plays (King Lear at the Arts Theatre in Cambridge a couple of months ago being the most recent example), it would be relatively easy to critique this aspect of Michael Young's argument - one hardly needs a specialism in feminism or Black Literature to question both the assertion that "their characters and relationships 
articulate for us almost universal truths" and their suitability for $100 \%$ of today's school population. So let me spend more time examining Michael's point about Newton's laws of motion.

Now, I'm all for teaching about Newton - especially if such teaching is enlivened about accounts of his personal life (he devoted much of his time and energies to denigrating anyone who disagreed with him or claimed, however justifiably, to have come up with some of his ideas before him, or even to have been of some assistance to him; he was such a bad lecturer that sometimes no students would remain - in which circumstances he simply continued to lecture as if the theatre was packed; he was obsessed by the possibilities of alchemy). But, speaking as someone who loves Newton's laws of motion and has spent quite a bit of time trying to teach them to secondary school students, I am left wondering how much the sum of human happiness is reduced for many who do not know or understand them. If anything, what I would rather most people appreciated is not so much the laws themselves but the implication that the same simple set of assumptions can be used to explain the rate at which an object falls in a school laboratory (I am all in favour of students continuing to calculate the value of acceleration due to gravity), the periodicity of a pendulum and the movement of both satellites and natural 'heavenly' objects - such as planets, stars and comets.

However, some primary school curricula require pupils to be able to show the direction in which forces act on objects and to appreciate the implications for motion when forces are not balanced. Yet we know (diSessa, 1993) that quite a high proportion of physics graduates find it difficult consistently to apply Newton's first ('If there is no net force on an object, then it continues in a straight line at constant speed') and third ('When a first body exerts a force $\mathbf{F}_{1}$ on a second body, the second body simultaneously exerts a force $\mathbf{F}_{2}$ on the first body equal to $-\mathbf{F}_{1}{ }^{\prime}$ ) laws of motion, let alone truly to have internalised them. A naïve conception of powerful knowledge can too easily lead to inappropriate curricula (Reiss \& White, 2014).

There are plenty of other examples in school science where too many students are forced to sit through material that is neither relevant for them nor intelligible to them. A particular bête noire of mine (I hope the term will not be seen by some as racist) is balancing chemical equations. I was the sort of school student who enjoyed balancing chemical equations and found it almost effortless to do so. I am in a minority. I have spent many, many hours watching fine secondary teachers attempting to get their students to be able to balance chemical equations so as to increase their chances of getting a crucial grade $C$ at GCSE level (Reiss, 2000). One conclusion I draw is that such teaching provides an effective means of giving some students a deep and long-lasting dislike of chemistry.

But, of course, there are some students - and I am one of them - for whom Newton's laws of motion and the knowledge of atomic theory and valency do indeed prove to be powerful. The point, surely, is that knowledge is not powerful independent of the knower. Rather, the fact that some knowledge is powerful tells us about the relationship between that piece of knowledge and the particular knower. A good education system is one that allows its school teachers to provide each learner with an education that enables them to acquire the knowledge, the skills and the understandings that prove powerful for them, enabling them 
to live lives that are more meaningful and exhibit greater flourishing than if education was left entirely in the hands of families and other extra-school influences.

\section{Conclusion}

Michael Young's ideas about the school curriculum and, in particular, his notion of 'powerful knowledge' are extremely helpful for us in thinking about the aims of education and the contents of curricula. Applied inflexibly or naively they could result in some students receiving an inappropriate education. Applied sensitively - with sensitivity both to different students and to different subjects - they have the potential to complement the work of other educationalists, including John White, and enrichen the education that schools provide. A start is being made on such fine-grained work - notably Lambert (2014) in respect of geography. It would be good to see such work extended to other subjects.

\section{References}

diSessa, A. A. (1993) Toward an epistemology of physics. Cognition and Instruction, 10, 105225.

Ehrlich, P. R. (1981) An ecologist standing up among seated social scientists. CoEvolution Quarterly, 31, 24-35.

Hirsch, Jr., E. D. (1996) The schools we need and why we don't have them. New York: Anchor Books.

Hirst, P. H. (1965) Liberal education and the nature of knowledge. In: Archambault, R. E. D. (Ed.) Philosophical analysis and education. London: Routledge \& Kegan Paul, pp.113138.

Lambert, D. (2014) Subject teachers in knowledge-led schools. In: Young, M. \& Lambert, D. with Roberts, C. \& Roberts, M. (2014) Knowledge and the future school: Curriculum and social justice. London: Bloomsbury, pp.159-187.

Reiss, M. J. (2000) Understanding science lessons: Five years of science teaching. Buckingham: Open University Press.

Reiss, M. J. (2005) Salters-Nuffield Advanced Biology (SNAB): a new advanced level biology course. Education in Science, 213, 22-23.

Reiss, M. J. (2015) The curriculum and subject knowledge. In: Suissa, J., Winstanley, C. \& Marples, R. (Eds) Education, philosophy and well-being: New perspectives on the work of John White. London: Routledge, pp.26-38.

Reiss, M. J. \& White, J. (2013) An aims-based curriculum: The significance of human flourishing for schools. London: IOE Press.

Reiss, M. J. \& White, J. (2014) An aims-based curriculum illustrated by the teaching of science in schools. The Curriculum Journal, 25, 76-89.

White. J. P. (1973) Towards a compulsory curriculum. London: Routledge \& Kegan Paul. White, J. (1996) The aims of school education. London: Institute for Public Policy Research. White, J. (2011). Exploring well-being in schools: A guide to making children's lives more fulfilling. London: Routledge.

Young, M. F. D. (2008) Bring knowledge back in: From social constructivism to social realism in the sociology of knowledge. London: Routledge. 
Young, M. (2014a) Knowledge, curriculum and the future school. In Young, M. \& Lambert, D. with Roberts, C. \& Roberts, M. (2014) Knowledge and the future school: Curriculum and social justice. London: Bloomsbury, pp.9-40.

White, M. (2014b). The curriculum and the entitlement to knowledge. Available at http://www.cambridgeassessment.org.uk/Images/166279-the-curriculum-and-theentitlement-to-knowledge-prof-michael-young.pdf.

Young, M. (2014c) Powerful knowledge as a curriculum principle. In Young, M. \& Lambert, D. with Roberts, C. \& Roberts, M. (2014) Knowledge and the future school: Curriculum and social justice. London: Bloomsbury, pp.65-88.

Young, M. \& Lambert, D. with Roberts, C. \& Roberts, M. (2014) Knowledge and the future school: Curriculum and social justice, Bloomsbury, London. 